\title{
Influence of Sociodemographic Factors and Behavioral Habits on Periodontal Disease Status
}

\author{
Sunny Mavi ${ }^{1}$ Sachitananad Arora ${ }^{2}$ Shivjot Chinna ${ }^{2}$ \\ Anirban Chatterjee ${ }^{4}$ Renu Reju' \\ 1Department of Periodontology, Sudha Rustagi College of Dental \\ Sciences and Research, Faridabad, Haryana, India \\ ${ }^{2}$ Department of Periodontology, ITS Dental College, Hospital and \\ Research Centre, Greater Noida, Uttar Pradesh, India \\ ${ }^{3}$ Department of Public Health Dentistry, Sudha Rustagi College of \\ Dental Sciences and Research, Faridabad, Haryana, India \\ ${ }^{4}$ Department of Periodontology, Oxford Dental College, Bangalore, \\ Karnataka, India
}

Dent J Adv Stud 2021;9:77-82.

\author{
$\begin{array}{ll}\text { C. S. Baiju } & \text { C. M. Marya } \\ & \end{array}$
}

Address for correspondence Sunny Mavi, BDS, MDS, H. No. 1283, Sec 21 D, Faridabad, Haryana, 121001, India (e-mail: snnymavi@gmail.com).

\begin{abstract}
Keywords

- gingivitis

- periodontal status

- socioeconomic status

Aim The aim of this study is to asses the influence of sociodemographic factors and behavioral habits on the periodontal disease status of the population in a selected region.

Methodology Data were collected using a self-structured questionnaire and clinical examination. Various sociodemographic variables such as gender, age, and socioeconomic status and behavioral habits, such as tobacco usage and oral hygiene practices, were factored into the questionnaire. Factors determining the socioeconomic status were education, work profile, and salary. The data were analyzed using Statistical Package for Social Sciences (SPSS 21, IBM Corp, 2015 Virginia, United States).

Results The total prevalence of periodontal disease was $94.6 \%$, out of which $90 \%$ had gingivitis and $4.6 \%$ had periodontitis. Only $5.4 \%$ of the population was healthy. In the present study, sociodemographic factors such as socioeconomic status, age, and gender were found to have a positive correlation with the periodontal disease status. Conclusion Since the treatment of periodontal disease is not simple and is expensive, it needs early intervention for its prevention.
\end{abstract}

\section{Introduction}

Changes in our knowledge of the etiology of periodontal disease, and the recognition of the potential importance of susceptibility factors as they affect initiation and progression of periodontal disease, have led to intense study of specific risk factors for periodontal diseases. ${ }^{1}$ It was previously believed that the population was universally susceptible to periodontal disease. ${ }^{2}$ Epidemiologic studies, such as the survey conducted by the National Centre for Health Statistics and those of the
National Institute of Dental Research, along with additional studies, have created a mountain of data with regard to the various risk factors, indicators, and determinants of periodontal disease. However, the relationship and the association of these factors may vary in different geographical regions. ${ }^{3}$

Therefore, this epidemiological study was undertaken among the population of Greater Noida with the aim to assess the influence of the sociodemographic factors and behavioral habits on the periodontal disease status of the population in this region.
DOI https://doi.org/ 10.1055/s-0041-1732915 ISSN 2321-1482 (c) 2021. Bhojia Dental College and Hospital affiliated to Himachal Pradesh University.

This is an open access article published by Thieme under the terms of the Creative Commons Attribution-NonDerivative-NonCommercial-License, permitting copying and reproduction so long as the original work is given appropriate credit. Contents may not be used for commercial purposes, or adapted, remixed, transformed or built upon. (https://creativecommons.org/licenses/by-nc-nd/4.0/).

Thieme Medical and Scientific Publishers Pvt. Ltd. A-12, 2nd Floor, Sector 2, Noida-201301 UP, India 


\section{Materials and Methods}

This cross-sectional study was conducted in the Department of Periodontics to determine the influence of sociodemographic factors and behavioral habits on periodontal health status among representative sample population of Greater Noida. Subjects in the age group of 18 to 75 years coming to institutional outpatient department were included in the study. Subjects undergoing or undergone any form of periodontal therapy in last 3 months or pregnant and lactating women or subjects with any systemic illness were excluded from the study.

Tobacco smokers were classified based on Centers for Disease Control and Prevention (CDC)'s classification for lifetime smoking habits. Tobacco smokers were classified based on CDC's classification for lifetime smoking status: as nonsmokers who had never smoked a cigarette or smoked fewer than 100 cigarettes in their entire lifetime; as former smokers who had smoked at least 100 cigarettes in their lifetime, but currently did not smoke currently; and lastly, as current smokers.

\section{Sample Size}

Assuming that the prevalence of periodontal diseases as per the previous epidemiological studies conducted is 75 to $85 \%^{2,3}$ in the Indian population and particularly in the western Uttar Pradesh region. ${ }^{3}$ The sample size was calculated using formula:

\section{$N=Z^{2} \alpha / 2^{*} P^{*}(1-P)^{*} D / E^{2}$}

As per the formula, a minimum of 823 subjects were required to be assessed for finding the periodontal disease prevalence, where $P$ is the prevalence, $E$ is the precision, $Z \alpha$ is normal deviation, and $D$ is design effect.

The subjects were classified into healthy, gingivitis, and periodontitis participants based on the modification of American Academy of Periodontology-Centers for Disease Control (AAP-CDC)'s classification of periodontal disease 2007. ${ }^{4}$ As per their oral hygiene practices, subjects were classified into two groups. Group I consisted of subjects who used a toothbrush and dentifrice, and group II consisted of subjects who used other indigenous methods such as daatun and mango leaf.

\section{Data Collection}

Data were collected using self-structured questionnaire and clinical examination. A self-structured questionnaire was devised and subjects were asked about various sociodemographic variables such as gender, age, socioeconomic status (SES; monthly income, education, occupation) and behavioral habits such as tobacco usage and oral hygiene practices. The factors determining the SES were education, work profile, and salary. The subjects were classified based on the Modified Kuppuswamy's socioeconomic scale. ${ }^{5}$ Convenience sampling was used for sample collection.

The clinical parameters taken were pocket probing depth (PPD), clinical attachment level (CAL), gingival index $(\mathrm{GI}){ }^{6}$ and oral hygiene index (simplified) by Greene and Vermillion. ${ }^{7}$ Means of PPD, CAL, and GI were calculated for each subject and used for the further statistical analysis.

\section{Statistical Analysis}

The data were analyzed using Statistical Package for Social Sciences (SPSS 21) (IBM Corp) for relevant statistical comparisons. One way analysis of variance (ANOVA) test was followed by Bonferroni's correction for posthoc comparison while comparing more than two groups on continuous, normally distributed variables. Multivariate logistic regression was performed for the calculation of odd's ratio, and chi-squared test was used for categorical variables. A level of $p<0.05$ was considered statistically significant.

\section{Results}

A total of 1,023 subjects were recruited in the study. Periodontal status of female subjects was found to be better as lesser number of female subjects were having periodontitis $(p<0.05)$ when compared using chi-squared test (-Table 1).

After obtaining overall significant difference using one-way ANOVA test, on posthoc evaluation (Bonferroni's test) of all the groups, a statistically significant difference was found between the healthy and gingivitis group as well as the healthy to periodontitis group and gingivitis and periodontitis group with a $p$-value $\leq 0.001$ that was statistically significant for mean GI, mean clinical attachment, mean pocket probing death w.r.t age, gender, SES, oral hygiene habits, and tobacco habits (-Table 2). According to gender, the odds ratio in gingivitis group for females was $1: 1.52$ with $p$-value of 0.154 and in the periodontitis group, odds ratio was 1: 0.62 with a $p$-value of 0.300 that was not statistically significant.

Table 1 Periodontal status according to gender

\begin{tabular}{|l|l|l|l|l|}
\hline Periodontal status & Male, $\boldsymbol{n}(\%)$ & Female, $\boldsymbol{n}(\%)$ & Total, $\boldsymbol{n}(\%)$ & $p$-Value \\
\hline Healthy & $37(6.1 \%)$ & $18(4.3 \%)$ & $55(5.4 \%)$ & $0.014^{*}$ \\
\hline Gingivitis & $529(87.9 \%)$ & $392(93.1 \%)$ & $921(90.0 \%)$ & $0.014^{*}$ \\
\hline Periodontitis & $36(6.0 \%)$ & $11(2.6 \%)$ & $47(4.6 \%)$ & $0.014^{*}$ \\
\hline Total & $602(100.0 \%)$ & $421(100.0 \%)$ & $1023(100.0)$ & \\
\hline
\end{tabular}

Note: ${ }^{*}$ highly significant 


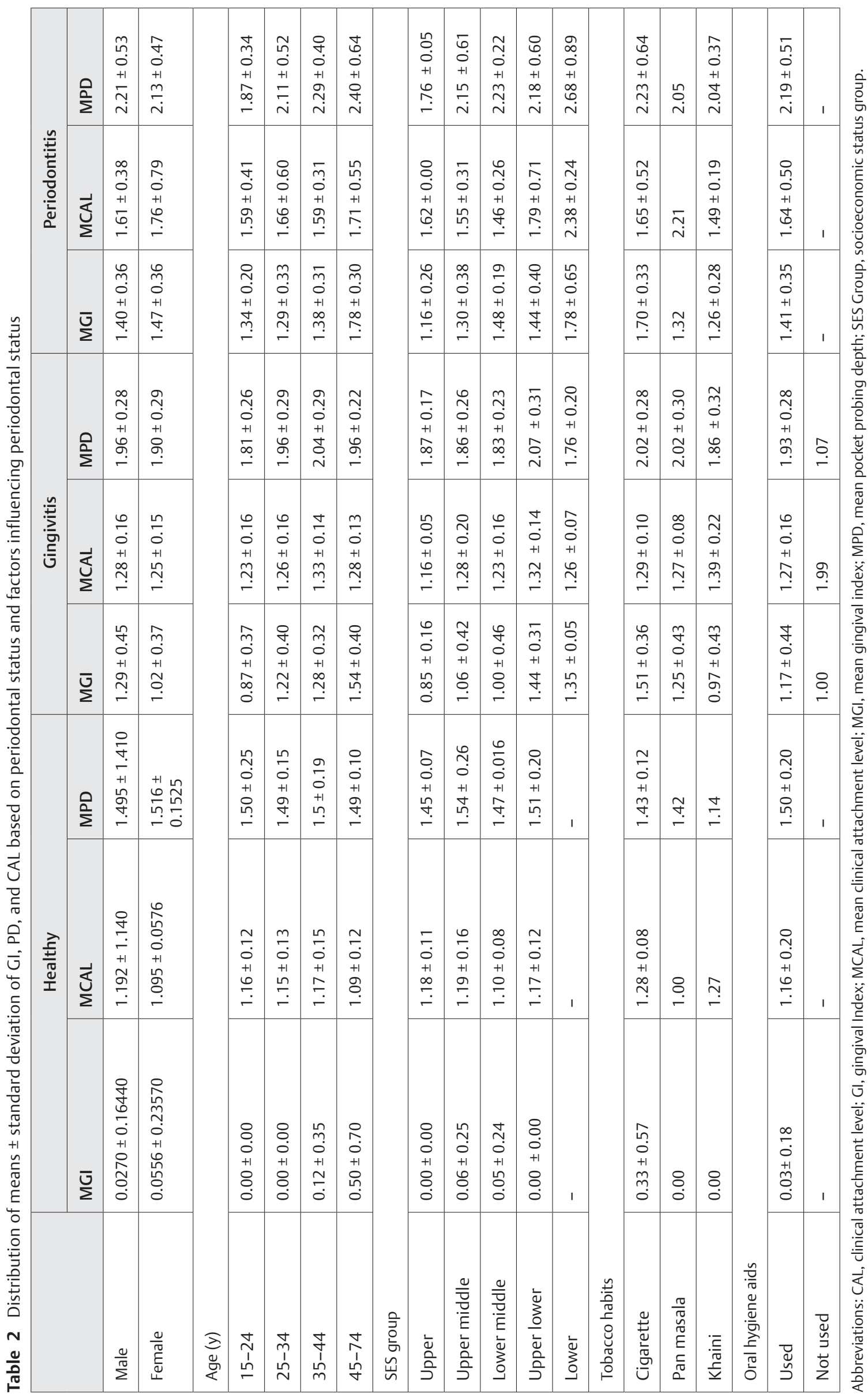


Table 3 Multivariate analysis for odd's ratio by least significant difference (logistic regression)

\begin{tabular}{|c|c|c|c|c|}
\hline & \multicolumn{2}{|c|}{ Gingivitis } & \multicolumn{2}{|c|}{ Periodontitis } \\
\hline & Odds ratio & $p$-Value & Odds ratio & $p$-Value \\
\hline \multicolumn{5}{|l|}{ Gender } \\
\hline Male & 1 & - & 1 & - \\
\hline Female & 1.52 & $0.154^{\mathrm{a}}$ & .62 & $0.300^{\mathrm{a}}$ \\
\hline \multicolumn{5}{|l|}{ Age $(y)$} \\
\hline $15-24$ & 1 & - & 1 & - \\
\hline $25-34$ & 4.15 & $0.012^{\mathrm{b}}$ & 5.26 & $0.007^{b}$ \\
\hline $35-44$ & 6.30 & $0.006^{\mathrm{b}}$ & 8.25 & $0.003^{b}$ \\
\hline $45-74$ & 17.46 & $0.023^{b}$ & 24.75 & $0.001^{\mathrm{b}}$ \\
\hline \multicolumn{5}{|l|}{ Socioeconomic status } \\
\hline Upper & 1 & - & 1 & - \\
\hline Upper middle & 0.93 & $0.879^{\mathrm{a}}$ & 2.84 & $0.237^{a}$ \\
\hline Lower middle & 2.27 & $0.080^{\mathrm{b}}$ & 2.88 & $0.229^{a}$ \\
\hline Upper lower-lower & 2.68 & $0.039^{b}$ & 4.20 & $0.101^{\mathrm{a}}$ \\
\hline \multicolumn{5}{|l|}{ Smoking tobacco habits } \\
\hline Group A (users) & 1 & - & 1 & - \\
\hline Group B (nonusers) & 1.32 & $0.014^{b}$ & 4.45 & $0.008^{b}$ \\
\hline \multicolumn{5}{|l|}{ Tobacco products used } \\
\hline Cigarette & 1 & - & 1 & - \\
\hline Pan masala & 4.42 & $0.013^{b}$ & 4.32 & $0.045^{\mathrm{b}}$ \\
\hline Khaini & 0.42 & $0.436^{\mathrm{a}}$ & 1.85 & $0.667^{\mathrm{a}}$ \\
\hline Gutkha & 0.71 & $0.750^{\mathrm{a}}$ & 16.66 & $0.009^{b}$ \\
\hline \multicolumn{5}{|l|}{ Oral hygiene practices } \\
\hline $\begin{array}{l}\text { Group I (Subjects } \\
\text { using tooth brush and } \\
\text { dentifrice) }\end{array}$ & 1 & - & 1 & - \\
\hline $\begin{array}{l}\text { Group II (Subjects using } \\
\text { other indigenous methods } \\
\text { like datum or mango leaf) }\end{array}$ & 2.26 & $0.012^{b}$ & 3.21 & $0.023^{b}$ \\
\hline
\end{tabular}

Note: Least significant difference (logistic regression) 95\% confidence interval

aStatistically insignificant.

bHighly significant.

Table 4 Association between socioeconomic status and history of smoking

\begin{tabular}{|l|l|l|l|l|}
\hline & \multicolumn{3}{|c|}{ Socioeconomic status (odds ratio) } \\
\hline & Upper & Upper middle & Lower middle & Upper lower and lower \\
\hline $\begin{array}{l}\text { History of smokeless tobacco } \\
\text { use }\end{array}$ & $0.42^{*}$ & $0.54^{*}$ & $0.77^{*}$ & $0.87^{*}$ \\
\hline $\begin{array}{l}\text { History of smoking tobacco } \\
\text { use }\end{array}$ & $0.22^{*}$ & $0.34^{*}$ & $0.67^{*}$ & $0.65^{*}$ \\
\hline No history of tobacco use & 1.00 & 1.00 & 1.00 & 1.00 \\
\hline
\end{tabular}

* highly significant

According to age, the odds ratio for gingivitis and periodontitis group was statistically significant. For the last statistical analysis, the upper lower and lower class were clubbed together. According to the socioeconomic scale, the odds ratio in gingivitis group and periodontitis group was not statistically significant. Based on the tobacco usage, the odds ratio in the gingivitis group for Group B when compared with
Group A was 1:1.32 $(p$-value $=0.014), 1: 4.42(p$-value $=0.013)$ for pan masala, 1:0.42 for khaini $(p$-value $=0.436), 1: 0.71$ $(p$-value $=0.750)$ for gutkha $(-$ Table 3$)$. Similarly, the odds ratio in the periodontitis group for Group B when compared with Group $A$ was $1: 4.45$ ( $p$-value for 0.008), 1:4.32 ( $p$-value $=$ 0.045 ) for pan masala, $1: 1.85$ ( $p$-value $=0.667)$ for khaini, and $16.66(p$-value $=0.009)$ for gutkha. For the oral hygiene 
practices, the odds ratio for subjects in Group II when compared with Group I was 1:2.26 ( $p$-value $=0.012$ ) in the gingivitis group and 1:3.21 ( $p$-value $=0.023)$ for the periodontitis group. Subjects with upper lower and lower SES were having the more history of smokeless tobacco use than nonsmoking tobacco ( - Table 4 ).

\section{Discussion}

Most of the periodontal diseases can be reversed in early stages; however, if they are not treated and progress, they can become painful, irreversible, and their complications usually remain for lifetime. ${ }^{8}$

The total prevalence of periodontal disease was $94.6 \%$ out of which $90 \%$ had gingivitis and $4.6 \%$ had periodontitis. Only $5.4 \%$ of the population was healthy. In the present study, sociodemographic factors such as SES, age, and gender were found to have a positive correlation with the periodontal disease status. The results of the present study were corroborated with a study done by Verma et $\mathrm{al}^{9}$ in another semirural region of Uttar Pradesh that also showed similar prevalence of $90 \%$ of periodontal diseases.

Multivariate analysis to compare the genders with respect to gingivitis revealed a greater odds ratio of 1:1.52 for females than males, although it was not statistically significant ( $p$-value $=0.154)$. According to Aletaha et al, ${ }^{10}$ the decreased odds ratio for periodontitis found among females could be attributed to their increased treatment seeking behavior. Higher gingivitis scores could be attributed to the fact that there are gingival inflammatory conditions found in females that are related to hormonal conditions.

The results of this study show a direct correlation between periodontal status and SES with a $p$-value less than 0.001 (statistically significant). Backlund et $\mathrm{al}^{11}$ said that analysis of the shape of socioeconomic-health gradient can lead to greater theoretical clarity about the production of health inequalities.

In this study, an attempt was made to evaluate the influence of tobacco on the periodontal status. Both smokeless and smoke tobacco users were clubbed into one group and nontobacco into another. The results of our study revealed a positive correlation between tobacco and periodontal status ( $p$-value $<0.05$ ). These results were in corroboration with an overwhelming body of data from multiple cross-sectional and longitudinal studies conducted by Kamath et al, ${ }^{12}$ which have demonstrated that pocket depth and clinical attachment loss were more prevalent and severe in patients who were tobacco users compared with nontobacco users. In the present study, we found that out of 1,023 subjects only one subject $(0.1 \%)$ did not practice any oral hygiene method whether it is tooth brushing or indigenous method. Keeping this in view, the subject was not assessed for data interpretation.

It has been documented that that occasional tooth brushing is associated with increased severity and extent of periodontal inflammation. On the other hand, periodontal inflammation and bleeding can affect the ability to clean the teeth effectively.
Since the effect of various adverse habits on GI, CAL, and probing depth was minimal, the confounding and modifying effect of smoking considered to be a risk of periodontal disease becomes limited.

\section{Limitations}

Despite larger sample size, a major limitation of the present study is underestimation of healthy subjects and overestimation of diseases because of convenience sampling design of the study.

\section{Conclusion}

To conclude the present study, it was seen that there was a statistically significant relation between the sociodemographic factors and behavioral habits on the periodontal status of the population. Certain striking associations were noted like an increase in the periodontal disease severity with decreasing socioeconomic level, old age associated with periodontal disease, and the gender bias shown by periodontal disease. Tobacco usage and use of indigenous aids for maintaining oral hygiene go hand-in-hand in causing periodontal disease.

A new generation of studies is needed not only to identify other potential risk factors for periodontal diseases but also to determine the effective interventions directed at modulating important risk factors and to assess their effects on the initiation and progression of periodontal disease, and their effects on periodontal therapy. Hence, the health policies by the government can be designed accordingly so as to maximally effect the different strata of the society.

\section{Conflict of Interest}

Nil.

\section{References}

1 AlJehani YA. Risk factors of periodontal disease: review of the literature. Int J Dent 2014;2014(Special Issue):182513

2 Nazir MA. Prevalence of periodontal disease, its association with systemic diseases and prevention. Int J Health Sci (Qassim 2017;11(2):72-80

3 Shaju JP, Zade RM, Das M. Prevalence of periodontitis in the Indian population: a literature review. J Indian Soc Periodontol 2011;15(1):29-34

4 Wei L, Evans MS, Genco RJ. AAP-CDC classification of periodontal disease. Update of the case definitions for population-based surveillance of periodontitis' Periodontol 2012;11:66-64

5 Sheikh S. Modified Kuppuswamy socioeconomic scale updated for the year 2018. Indian J Res 2018;7(3):435-436

6 World Health Organisation, Oral Health Surveys-Basic Methods. 4th edition. Geneva: World Health Organization Press; 2013 47-48

7 Greene JC, Vermillion JR. The simplified oral hygiene index. J Am Dent Assoc 1964;68:7-13

8 Loesche WJ, Grossman NS. Periodontal disease as a specific, albeit chronic, infection: diagnosis and treatment. Clin Microbiol Rev 2001;14(4):727-752

9 Verma SK, Kumar BD, Singh S, et al. Effect of gutkha chewing on periodontal health and oral hygiene of peoples in Delhi NCR region of North India: a cross-sectional multicentered study. J Family Med Prim Care 2019;8(2):564-567 
82 Sociodemographic Factors and Behavioral Habits affecting Periodontal Disease Mavi et al.

10 Aletaha D, Nell VP, Stamm T, et al. Acute phase reactants add little to composite disease activity indices for rheumatoid arthritis: validation of a clinical activity score. Arthritis Res Ther 2005;7(4):R796-R806

11 Backlund E, Sorlie PD, Johnson NJ. The shape of the relationship between income and mortality in the United States.
Evidence from the National Longitudinal Mortality Study. Ann Epidemiol 1996;6(1):12-20, discussion 21-22

12 Kamath KP, Mishra S, Anand PS. Smokeless tobacco use as a risk factor for periodontal disease. Front Public Health 2014;2:195 